\title{
The Study on the Sustainable Patterns of Grassroots Innovations in the Clusters of Micro-Enterprises
}

\author{
Yao-Chin Lin ${ }^{1}$, Chun-Liang Chen ${ }^{2}$, Wei-Hung Chen $^{3}$
}

\begin{abstract}
The purpose of this study is to find out different patterns of grassroots innovation under the circumstances of clustering and sustainable development of Micro-enterprises (MIEs). The research object is the clustering of MIEs in Taiwan. This study collects data through interviews, secondary data, observation and expert meeting etc. This study found four patterns promote the sustainable development of grassroots innovation. 1. Pattern I is ability high and trigger high, is defined as "Sustainable Development". 2. Pattern II is ability high and trigger low, is defined as "Abilityoriented". 3. Pattern III is ability low and trigger low, is defined as "Newborn". 4. Pattern IV is ability low and trigger high, is defined as "Leader-oriented". Moreover, the study identifies practical implications and proposes suggestions for future research. This study also provides clear guidance on government policies, clustering companies, counseling consultants, and the four patterns to promote sustainability.
\end{abstract}

Keywords: Grassroots Innovations, Micro-Enterprises' Cluster, Sustainability

\section{Introduction}

This study mainly investigated the cluster of 7 micro-enterprises in Taiwan. Cluster refers to a community including leader and companies which are cooperative organizations. Porter (1998) proposes the concept of clustering based on geographic location. Clustering cooperation can enhance the company's competitive advantage. In addition, grassroots innovation is a bottom-up innovation model. The definition of grassroots innovations proposed by Seyfang \& Smith (2007) can be connected with cluster theory. This study uses the abilities and triggers of micro-enterprises and summarizes the four types, and uses sustainable development perspectives to analyze. Ability refers to the related capacity or ICT capability of micro-enterprises in business operations. Trigger is a synonym for driving force. It is the force that leads the leaders of micro-enterprise clusters to positively and actively.

The purpose of this study is to find out different patterns of grassroots innovation under the circumstances of clustering and sustainable development of MIEs. Research questions are as follows:

1. What are the triggers and abilities of grassroots innovations in micro-enterprises' cluster?

2. What are the patterns of grassroots innovations in micro-enterprises' cluster?

3. How grassroots innovations in micro-enterprises' cluster to promote sustainable?

\footnotetext{
${ }^{1}$ Associate Professor, Department of Information Management, Yuan Ze University, Taiwan.

2 Associate Professor, Graduate School of Creative Industry Design, National Taiwan University of Arts, Taiwan.

${ }^{3}$ Ph.D., Department of Information Management, Yuan Ze University, Taiwan.
} 


\section{Literature Review}

The literature review, first, discusses the trigger factors and abilities of cluster sustainability for micro-enterprises, second, grassroots innovations and sustainable development, and finally, grassroots innovation model.

\subsection{Micro-Enterprises' Cluster Sustainability}

Porter (1998) argues that clusters are the focus of interconnected companies and institutions in specific areas. Since the early 1990s, research on clusters has increased significantly. Information technology added that the factors that influence the company's competitive advantage include: 1 . Increasing the company's productivity; 2 . Instructing the direction and pace of innovation; 3. Inspiring the composition of new business, which also expands and strengthens the cluster itself. Therefore, as part of a cluster, companies can increase productivity, gain more information, use technology, collaborate with related companies, and ultimately promote improvements and achieve better performance. Clusters act as generators and provide potential advantages when sensing the needs and opportunities for innovation (Porter \& Stern, 2001). Ketels \& Memedovic (2008) mentioned in the United Nations Industrial Development Organization (UNIDO) 50th anniversary publications. Clustering is a very important aspect of the modern economy. Clustering can lead to regional prosperity. Therefore, many countries have launched policies or plans related to cluster actively created an environment for the development of industrial clusters.

O'Malley, O'Dwyer, McNally \& Murphy (2014) pointed out that Ireland's Solid State Pharmacy Cluster (SSPC) works in a symbiotic way, supporting and improving the mutual cooperation and effective operation through bi-directional, symmetrical and synchronous feedback. Training can help SSPC become a successful and innovative collaboration between seemingly competing companies, thereby improving their ability to succeed in a highly competitive global market.

Cruz \& Teixeira (2010) divided the clusters into 10 categories through literature review: cluster pedigrees and evolutionary methods, agglomeration economies, knowledge-based, systems analysis or regional and national innovation systems, industrial policies and regional development policies, internationalization, global networks , Multinational corporations and local clusters, network and social clusters, institutional approaches to clustering, finance (eg mergers, acquisitions, risk analysis and stock markets), and ecological (eg energy and environmental risk) approaches.

Rao (2015) concluded that clusters can be defined as the aggregation of micro, small and medium-sized companies that perform similar production or supply of goods or services within the same or adjacent areas. Ingstrup (2013) supports clustering as an interorganizational configuration, and density can produce desirable results. The closeness of the cluster not only enables cluster members to collect resources and information, but also provides them with opportunities for sharing activities to achieve the common goals of the cluster.

Rani (2013) cited the drivers of MIE innovation: 1. The need to provide a range of quality products; 2 . More diversification and more comprehensive value; 3 . The need to modernize production and administrative procedures; 4. Improve Productivity; 5. 
Reducing costs; 6. Entering new markets and increasing participation in global markets, and finally; 7 . Increasing competitiveness.

Worldwide, the definition of a large number of employees in micro-enterprise employees is different. The Organisation for Organization for Economic Co-operation and Development (OECD) defines micro-enterprises as a company with fewer than 20 employees. MIE is a company with 5 or fewer employees. These businesses may be family or farm. MIE is in a leading position in the formation of enterprises and can be found in both developed and developing countries, whether rural or urban (Wolcott, Kamal \& Quureshi, 2008). Therefore, micro-enterprises usually refer to companies with fewer than five employees.

Regarding ability, Parida \& Örtqvist (2015) pointed out that Information and Communication Technology (ICT) capabilities influence the dynamic capabilities of small businesses. Specifically, the use of internal efficiency by ICTs has had a positive impact on adaptive capacity. The cooperative use of ICTs has had a positive impact on network capabilities and has also had a positive impact on adaptability and innovation capabilities. They define ICT capabilities as the internal use of IT, collaboration, and communications. Non-ICT capabilities refer to other capabilities beyond ICT, including product and brand design, brand marketing, management, and collaboration.

Through the discussion in this section of the literature, MIEs can use a group of people through grassroots clusters to innovate, collaborate and achieve sustainable development.

\subsection{Grassroots Innovations and Sustainable Development}

Seyfang \& Smith (2007) define grassroots innovations as follows: We use the term grassroots innovations to describe networks of activists and organizations generating novel bottom-up solutions for sustainable development; solutions that respond to the local situation and the interests and values of the communities involved. In contrast to mainstream business greening, grassroots initiatives operate in civil society arenas and involve committed activists experimenting with social innovations as well as using greener technologies. Seyfang \& Longhurst (2016) believes that grassroots innovation is very strong. They conducted sample surveys on 12 regions. Through the financial assistance of the government or related organizations, it will inevitably extend innovation and development, and economic forces cannot be ignored.

Pansera \& Sarkar (2016) studied how scarce resource entrepreneurs solve their problems and summed up three dimensions of grassroots innovation: sustainable development innovation, thrifty innovation process, and socially driven innovation. Their research shows that the intersection of these three dimensions provides space for three different interaction domains: 1. The sustainability-driven innovation and conservation-based innovation process involves more efficient products or services and less environmental impact; The process of conservation-oriented innovation and socially-driven innovation includes affordable products or services, and tailor-made solutions for the poor and society; 3. Sustainable development-driven innovation and socially-driven innovation involve environmental integrity sex and resilience. Bhatti (2012) defines thrift innovation as an innovation that redefines the business model, resets the value chain and redesigns the product to use resources in different ways, and creates more by providing users with 
affordability limits in a scalable and sustainable manner. Inclusive market.

Faherty \& Stephens (2016) recommends simplifying innovation and launching an innovation program specifically for MIE. MIE sees innovation as a complex activity related to the research and development of high-level technologies.

Oliver Sanz (2016) concluded that CC's participation was mainly a response to ideological motivation and became a kind of radicalism. The indicators of value, motivation, and perceived social benefits are similar to those shown in the previous CC and G.I. Research shows that transcendence is the strength of commitment. The main values promoted by social justice, ecology, and the local economy place these initiatives at the grassroots level and aim to promote the transition to viable and sustainable communities.

Tseng and Shih (2008) proposed that cluster innovations come from diversified development under multi-directional crossover. In addition to maintaining the original cluster network, micro-enterprises need to explore new networks through cluster innovation and rebuild new and old networks. The combination of networks has expanded the company's scale, improved its industrial efficiency, and most importantly, it has increased its ability to innovate. In addition to the partners in the cluster, participation in exhibitions and cross-industry cooperation may use new innovative products or services, not only within the same industry, but also across industry boundaries to gain better mutual support.

Seyfang \& Haxeltine (2012) expressed dissatisfaction with the new empirical study of the UK's transitional township movement ("grassroots innovation") and assessed its attempt to develop and influence a broader social and social technology system. This shows that the areas in which the theory can be refined can better explain the development of grassroots innovations and their wider impact - that is, understanding the importance of identity and group formation through a more comprehensive understanding of the importance of internal niche processes., And to address social changes in the grassroots innovation.

Smith \& Seyfang (2013) pointed out that one of the divisions in sustainable development is the division between grassroots environmental actions (participation conditions are generally considered to be good) and green innovation. Green innovation is usually centered on corporate technology and is considered to be ecological. Modernization is beneficial. This particular part focuses on an obvious missing link: sustainable innovation at the grassroots level.

Sipa (2017) mentioned that small businesses must continuously improve their competitiveness through innovation. Firms that are innovative and competitive have demonstrated stability in terms of goals and thus have determined the direction in which innovation will be implemented. Deleskiewicz (2014) pointed out that innovation is very important to modern economic development and is also a major factor in proving the competitiveness of enterprises. Corporate sustainable development is composed of three parts: community, environment and economy.

\subsection{The Patterns of Grassroots Innovations}

Nair, Tiwari \& Buse (2017) classify grassroots innovation into two types: radical innovation and incremental innovation. Radical innovation believes that productivity is 
the most important, and then cost and efficiency are the least important parts. Incremental innovation shows that comfort and usability are the absolute characteristics of innovation. Followed by productivity and cost. Productivity costs are undoubtedly an important feature that grassroots innovators consider when they innovate.

The object of this study is the government program, which divides the cluster into three types. As described below:

1. Types of Share: This type is knowledge-intensive micro-enterprise. The main purpose is to assist other micro-enterprises in the cluster to promote the clustering effect of members' upgrading and transformation, resource links and market expansion.

2. Types of Alliance: By the leaders of the cluster through the experience of transmission, share resources and management experience. The above is to help other micro-enterprise members in the cluster improve their management knowledge, make them grow strong, and then give play to the cluster effect of upgrading and transformation, resource linkages and market expansion.

3. Types of Guide: This type is assisted by a professional counseling team, in accordance with the actual situation of the group members to assist 1. Provide guidance for business development, 2. The establishment of common operating mode, 3. Members of the establishment of trust and cohesion centripetal catalysis. Finally, promoting the development of members into groups that operate independently and independently to create follow-up and diversified tutoring effectiveness.

This study defines sustainable patterns of grassroots innovations that use abilities and triggers to evaluate. We define triggers as leadership, member's needs and knowledge sharing. Abilities for management, product design, marketing, brand and IT Ability.

\section{Methodology}

\subsection{Research Design}

The purpose of this study is to find out different patterns of grassroots innovation under the circumstances of clustering and sustainable development of MIEs. Cluster triggers and abilities in MIEs is affects grassroots innovations' patterns, finally promote the MIEs to be sustainable development. Figure 1 shows the research framework.

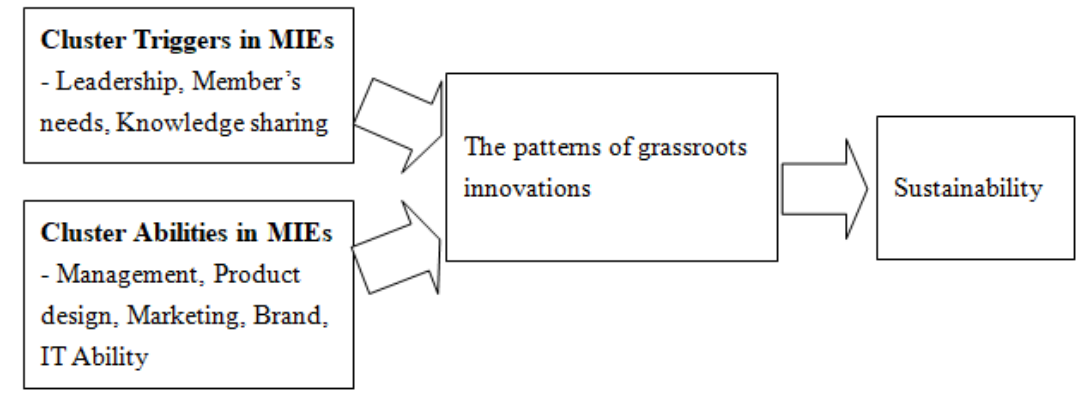

Figure 1: Research design

In this study, we propose the following four different methods. Subjects and data collection process included interview process records, verbatim interviews, secondary 
data collection, observations, and expert meetings. Interviews were recorded using tape recorders and video cameras with the consent of the respondents. Respondents also recorded the content in the paper to ensure the correctness of the recorded content. Three days after the interview, the content was entered into the transcript, and the interviewer was asked to modify the transcript according to the record to improve the reliability and validity of the interview.

Data collect was conducted by using and classifying data collected from 7 interviews. The average interview time is one hour. Secondary data for this study included the cluster consultation report for 2016, the 14 mid-term and final reports, and 7 sets of proposals. In this study, the subjects were selected by sampling and the subjects were asked to choose the sample that was most suitable for the purpose of the study. This is also called judgment sampling. Direct observations were conducted during the cluster meetings and interviews. Record the interactions between members and their expressions and reactions to issues related to their leaders. The results obtained are used to validate the members' answers to the cluster interaction questionnaire.

\section{Interview}

Find out the triggers and abilities of grassroots innovations in micro-enterprise clusters through interviews. Then, classify grassroots innovations from interview data.

2.Secondary data

The use of secondary data is an important way to learn about the company's capabilities. Get relevant information from reports provided by 7 clusters. Analyze the factors of sustainable development of MIEs

\section{Observation}

The observation method is mainly used to learn the ability and tendency of group gathering, observe the members' discussion and the interaction with the leaders during the cluster gathering.

4.Expert meeting

In the analysis of two academic experts, the seven clusters will be classified into four categories for sustainable development. And give suggestion on sustainable development Table 1 shows a comparison table of research questions and methods.

Table 1. Question and Mothed

\begin{tabular}{|c|c|}
\hline Question & Mothed \\
\hline $\begin{array}{l}\text { 1. What are the triggers and abilities of } \\
\text { grassroots innovations in micro-enterprises' } \\
\text { cluster? }\end{array}$ & $\begin{array}{l}\text { Interview } \\
\text { Observation } \\
\text { Secondary data }\end{array}$ \\
\hline $\begin{array}{l}\text { 2. What are the patterns of grassroots } \\
\text { innovations in micro-enterprises' cluster? }\end{array}$ & $\begin{array}{l}\text { Interview } \\
\text { Secondary data } \\
\text { expert meeting }\end{array}$ \\
\hline $\begin{array}{l}\text { 3. How grassroots innovations in micro- } \\
\text { enterprises' cluster to promote sustainable? }\end{array}$ & $\begin{array}{l}\text { Secondary data } \\
\text { expert meeting }\end{array}$ \\
\hline
\end{tabular}

According to the definition of the case study data by Yin (1994), the secondary data of this study include the 2016 cluster consultation report, 14 mid-term and final reports, and 7 proposals. In this study, the subjects were selected by sampling and the subjects were asked to select the samples that are most suitable for the purpose of the study. This 
is also called judgment sampling. The logic and validity of sampling are based on the indepth study of information-rich cases. Therefore, the research team commissioned colleagues from relevant organizations to choose the integration of networks and successful cases. Table 2 lists the codes, major commodities, and number of members for the seven clusters.

Table 2. Interview Objects

\begin{tabular}{cccl}
\hline NO & Code & Number of Members & Major Commodities \\
\hline 1 & S1 & 18 & organic goods \\
2 & E1 & 15 & handicrafts \\
3 & S2 & 15 & wedding-related industries \\
4 & N1 & 15 & food-based souvenirs \\
5 & M1 & 15 & food-based souvenirs \\
6 & N2 & 15 & handicrafts \\
7 & M2 & 16 & food-based souvenirs \\
\hline
\end{tabular}

\subsection{Data Analysis}

In this study, we analyze the patterns using mathematical quadrant and divide the patterns into four categories. The horizontal axis is the ability, Vertical is the trigger, as described in figure 2. Pattern $I$ is the representative ability high and trigger high, Pattern II is ability high and trigger low, Pattern III is ability low and trigger low, Pattern IV is ability low and trigger high.

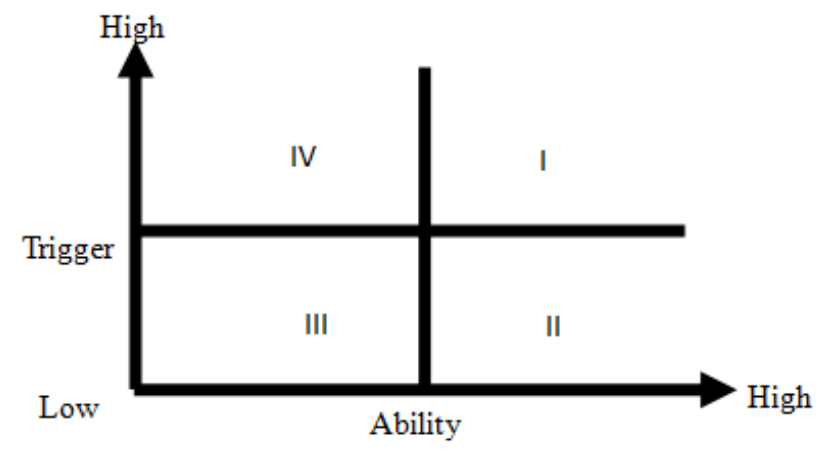

Figure 2: The analysis method of this study

\section{Findings}

\subsection{The Triggers and Abilities of Grassroots Innovations in Micro-Enterprises' Cluster}

The triggers for the clustering of MIEs can be analysis from the cluster leader, member's needs, knowledge sharing, information technology and so on. 1.Leader: is responsible for arranging regular meetings, counseling needs and other work, which is the important role of cluster cooperation and innovation. According to the results of the interviews, observations and secondary data, it is proved that the leaders are a very important driving force in the cluster. This is a make sense evidence. 2.Member's needs: 
Agglomeration is due to the needs of MIEs, and to meet the needs of the cluster style. 3.Knowledge sharing: Experience can be shared through leaders or experienced members. In addition, counselors can help diagnose problems with MIEs and share experience in business management. Abilities including, 1.Management ability: Production and operation management, Marketing management, Human resource management, Research \& development management(technology management), Finance management. 2.Product design ability: Product development and design, quality management, packaging design capabilities. 3.Marketing ability: Marketing capabilities, including product presentation skills, cross-border sales need to pay attention to international business. 4.Brand ability: Brand is an important asset of an enterprise. The creation of a brand needs constant accumulation. The brand image includes functional image, empirical image and symbolic image. Brand attitude includes brand trust, brand emotion and purchase intention. 5.Information technology ability: Science and technology and service capabilities, transport platform attributes and operational database analysis, the use of keywords, gold flow, logistics, cross-border e-commerce also pay attention to the difference between the platform.

\subsection{The Patterns of Grassroots Innovations Sustainable Development}

This study found four patterns to promote the sustainable development of grassroots innovation.

1. Pattern I is ability high and trigger high, this study is defined as a type of "Sustainable Development". This type of cluster is a model that can operate on its own, and is a demonstration cluster for sustainable development. This type can become an ecosystem in the future, and may be breeding a variety of different types of clusters. The representative cases are "N2" and "S2". Because of the excellent performance of the N2 case, the cluster leader have provided a variety of channels and good capabilities to assist member marketing. S2 has a good ability, and the overall enthusiasm and motivation are good.

2. Pattern II is ability high and trigger low, this study is defined as a type of "Abilityoriented". This group of members with high ability, but the lack of motivation. Trigger can be promoted through government incentives. This type can start from the ability to enhance the leadership, and become sustainable development type. The representative cases are "N1", "M1" and "M2". In these three representative cases, the cluster leaders have strong abilities, but they regard the clusters as the performance of the company or the association.

3.Pattern III is ability low and trigger low, this study is defined as a type of "Newborn". This type of group want to establish a cluster, but lack the ability and motivation. The representative case is "S1". The leader of the S1 cluster has ideas but the ability is weak and cannot be achieved. So, He is not active in the leadership of clustering.

4. Pattern IV is ability low and trigger high, this study is defined as a type of "Leaderoriented". This type can be counseled through the strategy, such as cross-group cooperation, to promote the formation of clustering prototype. The representative case is "E1". The leader of E1 is a typical leader and has strong leadership. Therefore, there is a strong triggers, but lack of ability. 


\section{Conclusion}

Lin, Chen \& Heng (2018) study pointed out that there are three types of cluster: brand model, clustering innovation model and e-commerce platform model. Gorgani (2014) proposed e-commerce is rapidly developing due to its potential as a green business, democratic partnership and economic opportunity. The abilities of this study include e-commerce capabilities. This study is consistent with the above two articles and promotes sustainable development through e-commerce.

Nair, Tiwari \& Buse (2017) pointed out that triggers are altruism, traditional knowledge, need, occupational observation and hobby. In order to divide grassroots innovation into two types. However, this study analyzes grassroots innovations from both triggers and abilities perspectives and presents different findings. Pattern I is a type of "Sustainable Development", how do other types change or improve to become Pattern I? Pattern II lacks triggers. Therefore, encouragement mechanisms can be used to promote this type of triggers. For example: increase in government grants, public praise, etc. Pattern III method of improvement. This study suggests that counselors should be strengthened to improve trigger and ability. It can become a type of sustainable development in the future. Pattern IV is the simplest, that is, to strengthen the capacity of the leader of the cluster, it can make this type of clustering sustainable development.

\section{Reference}

Bhatti, Y. A. (2012). What is frugal, what is innovation? Towards a theory of frugal innovation.

Cruz SCS, Teixeira AAC. (2010). The evolution of the cluster literature: Shedding light on the regional studies-regional science debate. Regional Studies. 44(9):1263-88.

Derlukiewicz, N. (2014). Development of Smart and Sustainable Economy in the European Union. European Journal of Sustainable Development, 3, 4, 151-162. Doi: 10.14207/ejsd.2014.v3n4p151.

Faherty, U., \& Stephens, S. (2016). Innovation in micro enterprises: Reality or fiction? Journal of Small Business and Enterprise Development. 23(2), 349-362. doi:10.1108/JSBED-11-2013-0176

Golla, Silvana Saionara \& Pedroza, Eugenio Avila (2006)"Framework for analysis of the Types of Innovations".

Gorgani, M. (2014). Electronic Commerce as a Sustainable Business. European Journal of Sustainable Development, 3, 3, 141-148. Doi: 10.14207/ejsd.2014.v3n3p141.

Ingstrup MB. (2013). Facilitating different types of clusters. Management Revue. 24(2):133-150.

Kastrati1, V. (2015). Technological Innovation of Small and Medium Enterprises in Kosovo: Challenges and Barriers. European Journal of Sustainable Development, 4, 3, 145-150. Doi: 10.14207/ejsd.2015.v4n3p145.

Ketels, C. H. M., \& Memedovic, O. (2008). From clusters to cluster-based economic development. International Journal of Technological Learning, Innovation and Development, 1(3), 375-392. doi:10.1504/IJTLID.2008.019979

Lin, Y.C., Chen, W.H., \& Heng, X.-S. (2018). The Impact of Technological Capabilities on Online-toOffline Commerce: A Case of Micro-enterprises' Cluster Performance. International Journal of eEducation, e-Business, e-Management and e-Learning, 8. 1-9. doi: 10.17706/ijeeee.2018.8.1.1-9.

Nair A.K., Tiwari R., Buse S. (2017). Emerging Patterns of Grassroots Innovations: Results of a Conceptual Study Based on Selected Cases from India. In: Herstatt C., Tiwari R. (eds) Lead Market India. India Studies in Business and Economics. Springer, Cham

Oliver Sanz, E. (2016). The potential of Grassroots Innovations for sustainability strategies: a case study of the Spanish Community Currencies. Eu-SPRI Forum Early Career Researcher Conference (ECC):"Science, Innovation and the University: keys to social impact" Valencia, Spain. 13,14 and 15 April. 
O'Malley L, O'Dwyer M, McNally RC, Murphy S. (2014). Identity, collaboration and radical innovation: The role of dual organisation identification. Industrial Marketing Management. 43(8):1335-42.

Pansera, M., \& Sarkar, S. (2016). Crafting sustainable development solutions: Frugal innovations of grassroots entrepreneurs. Sustainability (Switzerland), 8(1), 1-51. doi:10.3390/su8010051

Parida, V., \& Örtqvist, D. (2015). Interactive effects of network capability, ICT capability, and financial slack on Technology- Based small firm innovation performance. Journal of Small Business Management, 53(S1), 278-298. doi:10.1111/jsbm.12191

Porter, M. E. (1998). Clusters and the new economics of competition. United States: Harvard Business School Press.

Porter, M. E., \& Stern, S. (2001). Innovation: Location matters. MIT Sloan Management Review, 42(4), 2836.

Rani, K. M. (2013). Innovation in indian women micro-enterprises. IPE Journal of Management, 3(2), 76-94.

Rao, J. M. (2015). Challenges to Innovation in Small Business Enterprise Sector in India. In International Interadisciplinary Business-Economics Advancement Conference (Vol. 87, No. 49.4, p. 164).

Seyfang G, Haxeltine A. (2012). Growing grassroots innovations: Exploring the role of community-based initiatives in governing sustainable energy transitions. Environment and Planning C: Government and Policy. 30(3):381-400.

Seyfang, G., \& Longhurst, N. (2016). What influences the diffusion of grassroots innovations for sustainability? Investigating community currency niches. Technology Analysis \& Strategic Management. 28(1), 1-23. doi:10.1080/09537325.2015.1063603

Seyfang, G., \& Smith, A. (2007). Grassroots innovations for sustainable development: Towards a new research and policy agenda. Environmental Politics. 16(4), 584-603.

Sipa, M. (2017). Innovation as a Key Factors of Small Business Competition. European Journal of Sustainable Development, 6, 1, 344-356 ISSN: 2239-5938.Doi: 10.14207/ejsd.2017.v6n1p344.

Smith A, Seyfang G. (2013). Constructing grassroots innovations for sustainability. Global Environmental Change. 23(5):827-9.

Tseng, C.C., \& Shih, C.C. (2008). Industrial Cluster Innovation: The Case of Koji Pottery. Journal of Entrepreneurship Research, 3 (4), 25-37.

Wolcott, P., Kamal, M., \& Qureshi, S. (2008). Meeting the challenges of ICT adoption by micro-enterprises. Journal of Enterprise Information Management, 21(6), 616-632. 